\title{
Celebrating 20 years of cell biology
}

\author{
This year marks the twentieth anniversary of the launch of Nature Cell Biology. We take this opportunity to reflect \\ on the progress in cell biological research and the evolution of our journal, and to celebrate the start of our third \\ decade with a special Focus on 20 years of cell biology.
}

T he year 1999 was an interesting one for science. The Nobel Prize in Physiology and Medicine was awarded to Günter Blobel, a distinguished cell biologist, 'for the discovery that proteins have intrinsic signals that govern their transport and localization in the cell'. Dolly the sheep, the first mammal to be cloned by somatic cell nuclear transfer in 1997, was back in the news after reports that, biologically, she might have aged prematurely (Nature 399, 316-317; 1999). The ethics of research that touched on human development, including human cloning and the - then nascent - field of human pluripotent stem cells (Science 282, 1145-1147; 1998), were being hotly debated. Computers and the Internet had permeated daily life and even though the world was gripped with anxiety over the Y2K bug, scientific publishing was continuing its steady move to a digital existence.

This was the world that Nature Cell Biology was born into, aiming, as stated in our first Editorial, to provide "a new interdisciplinary forum designed to foster the exchange of ideas between all areas of cell biology" (Nat. Cell Biol. 1, E1-E2; 1999). That same Editorial noted that "understanding how cells function and communicate with each other is one of biology's great challenges, and unravelling the fundamental molecular processes responsible defines the core of cell biology", thus setting the journal's scope to encompass cell biology in the broadest sense.

In 2019, the journal's mission remains unaltered and our scope continues to embrace the whole of cell biology while evolving with the research communities we serve. To celebrate our 20-year milestone we are delighted to present our Focus on '20 years of cell biology' (https://www.nature. com/collections/ylitpnslfp). The Focus includes 16 specially commissioned Review and Perspective articles that span the journal's purview. Although the breadth of cell biology could never be covered in 16 articles, we hope that collectively they highlight its diversity and impact. The Focus is accompanied by an online collection of research papers published in Nature Cell Biology over the last two decades, organised thematically under 'cell and molecular biology', 'stem cells and development' and 'physiology and disease'. Putting together this library proved a nearly impossible task and space limitations meant that we had to make difficult decisions. Thus, the collection is not intended to be comprehensive, but rather to provide a snapshot of 20 years of cell biology, as seen through the pages of our journal.

By studying the fundamental unit of life, cell biology represents one of the most exciting and versatile areas of research. Over the last two decades, technological advances have continually spurred progress by shattering barriers in imaging resolution, high-throughput and single-cell analyses, in vitro and in vivo models, and molecular and biophysical approaches. Areas that investigate essential processes, such as cell division and death, cell adhesion and migration, membrane and organelle biology, metabolism and stress responses, signal transduction and gene expression, have remained at the core of the journal but have become enriched with new approaches that often involve computational biology and biophysics. Interdisciplinary areas that we championed from early on, such as mechanobiology, have flourished and gained increased interest with time. From its early years the journal nurtured the stem cell and development fields as ones that yield significant cell biological insights, and they now occupy roughly a quarter of our content. Similarly, studies on the mechanisms that underlie physiology and disease have gained prominence in our pages over the last decade, with cancer biology in particular representing a fourth of our published papers.

What has remained immutable through the years is our commitment to the scientific community and the research papers that are entrusted to us. We, the editors of Nature Cell Biology, feel keenly both the privilege and responsibility of our role. We appreciate that the route to publication can be complex and sometimes frustrating. We have and will continue to engage closely with our authors, referees and readers to improve the editorial and peer-review process, and have undertaken many efforts to that end. Since 2014,

editorial decisions that invite resubmission circumscribe the scope of the revisions by providing detailed guidance on the points that should be addressed with priority and, where applicable, points that are deemed nonessential for eventual publication

(Nat. Cell Biol. 16, 1127; 2014). Manuscript

transfer between the Nature journals was already in place in 1999, but Nature Cell Biology was instrumental in the later development of the inter-journal consultation option: with author permission, the editor intending to decline a manuscript may consult with the colleagues of a sister journal on whether they would invite a transfer with a view to expediting publication.

We have also championed reproducibility and transparency initiatives. We have been publishing unprocessed images of gels/ blots for a decade. Last year we moved to mandating that these images, together with the numerical data behind graphs, be included in all revisions as part of the peer-review ahead of eventual publication. Since 2012, we have also been among the journals requesting information on statistical analyses in the form of a 'statistics checklist' for papers under formal review, an initiative that morphed into the Reporting Checklist of the Nature Research Journals (Nat. Cell Biol. 15,$443 ; 2013$ ) and, later, into the current Reporting Summary and Editorial Policy Checklist (Nat. Cell Biol. 19, 741; 2017). More recently, we piloted the publication of 'data availability statements' (Nat. Cell Biol. 19, 259; 2017) and ORCID identifiers for corresponding authors (Nat. Cell Biol. 19, 579; 2017), policies that have now been adopted across the Nature journals. We are pleased that these efforts have been embraced by our authors, and remain in close interaction with the community as we plan bolder transparency initiatives.

As we reflect on our 20-year journey, we also think about the faces behind the journal. We thank all our past Nature Cell Biology colleagues for building this journal with us. Most importantly a huge thanks to the people without whom none of this would be possible: our authors, for trusting us with your research; our referees, for offering your advice and time; and our readers, for your continued support. As we enter our third decade, we renew our commitment to serve the cell biology community with integrity and passion for the field and the scientific process. We hope you enjoy our Focus and look forward to the next 20 years of unravelling the mysteries of cell biology.

Published online: 2 January 2019 https://doi.org/10.1038/s41556-018-0262-5 